Marquette University

e-Publications@Marquette

Marketing Faculty Research and Publications

Marketing, Department of

$1-1-2002$

\title{
Ethical Myopia: The Case of "Framing" by Framing
}

Alan E. Singer

Steven Lysonski

Marquette University, steven.lysonski@marquette.edu

Ming Singer

David Hayes

Published version. "Ethical Myopia: The Case of 'Framing' by Framing," in Ethical Issues in Business: A Philosophical Approach, 7/E. Thomas Donaldson, Patricia H. Werhane, and Margaret Cording. Upper Saddle River, N.J. : Prentice Hall, 2002, pp. 456-66. Publisher Link. (C) 2002 Prentice Hall. 


\title{
Ethical Myopia: The Case of "Framing" by Framing
}

\author{
Alan E. Singer Steven Lysonski \\ Ming Singer $\bigcirc$ DaVid Hayes
}

\section{INTRODUCTION}

Substantial recent research in management and marketing science has explored the practical implications of systematic patterns of bias and heuristic-use in human decision-making. Researchers have proposed several applications of the emergent cognitive models in administrative and marketing contexts. These applications have included:

- Using particular heuristics to influence subordinates' commitment to a proposal (Schwenk, 1986)

- Attempting to influence customers (i.e., consumers and corporate buyers) by appealing to framing-effects, reference-prices and other biases (Thaler, 1985; Puto, 1987; Urbany et al., 1988)

- Modelling aggregate-level equilibrium market processes (Russell and Thaler, 1985; Kahneman, et al., 1986)

- Explaining investors' preferences for cash dividends over capital gains, with implications for dividend policy (Sheffrin and Statman, 1984)

- Viewing negotiations as strategic interactions between faulty cognitive systems, with implications for bargaining tactics (Neale and Bazerman, 1985)

- Using framing effects to influence sequential investment decision-making processes (Whyte, 1986).

With only one exception, all of these applications of cognitive models have been proposed and investigated without any reference to the ethical issues involved, such as utilitarian justification, fairness, deception, or exploitation. The only recorded exception to this surprizing ethical myopia is Schwenk's (1986) observation that where senior management use techniques of persuasion based on subordinates' cognitive heuristic-use, like vivid but unrepresentative anecdotes, the practice possibly infringes the subordinates' rights.

Ethical myopia is particularly evident in some of the associated recent developments in marketing science. Recently, some sophisticated marketing techniques based on cognitive models have been described and implicitly advocated, without any reference to ethics, nor social responsibility. These new model-based techniques appeal to the imperfect but often systematic decision-making processes of individual buyers or consumers. In the underlying models, particularly Prospect Theory (Kahneman and Trersky, 1979) and Transaction Utility Theory (Thaler, 1985) the concepts of mental accounting, framing and transaction-utilities are employed. In the preliminary section of this paper, therefore, these concepts are described briefly with reference to examples of the associated marketing techniques. Some ethical issues surrounding proposed applications to marketing are then explored.

From fournal of Business Ethics 10:29-36, 1991. Copyright by Kluwer Academic Publishers. Reprinted with kind permission of Kluwer Academic Publishers. 
These ethical explorations are structured around three themes. First, the utilitarian justification for using the model-based techniques is considered. Given the original context in which the techniques were proposed, a plausible utilitarian justification could exist. However, in many other marketing contexts, where use of the same techniques could also increase the seller's profits, it is much more difficult to justify their use with reference to consequential costs and benefits. The second theme examined concerns the more general marketing practice of encouraging customers to hold false beliefs, or to make inappropriate inferences, when making purchasing decisions. Objections to that type of marketing practice then apply a forteriori to some of the proposed special applications of Prospect Theory (PT) and Transaction Utility Theory (TUT). Finally, there is a discussion of the claim that the new techniques and tactics are purely scientific and therefore value-free.

\section{Mental Accounting, Framing and Utility}

This section describes very briefly some of the new concepts employed in the marketing models.

\section{Mental Accounting}

The concept of a "mental account," as it is now used in consumer behavior theory, originated from Tversky and Kahneman's (1981) "Theatre Ticket" experiment. In that experiment, subjects were asked:

Imagine that you have decided to see a play where admission is $\$ 10$ per ticket. As you enter the theatre you discover that you have lost the $\$ 10$ bill. Would you still pay $\$ 10$ to see the play?

Responses obtained were "Yes," 88\%; "No," 12\%. Another group of subjects were then asked:

Imagine that you have decided to see a play and paid the admission price of $\$ 10$ per ticket. As you enter the theatre you discover that you have lost the ticket. The seat was not marked and the ticket cannot be recovered. Would you pay $\$ 10$ for another ticket?

Responses obtained were "Yes," 46\%; "No," 54\%. Others have reported similar data in replications (e.g., Singer et al., 1986). The contrasting responses obtained to the two versions of the "Theatre Ticket" problem clearly demonstrate the effect of minor details or context on individual's preference and choice. The findings cannot be explained in terms of wealth-related outcomes alone, as in traditional economic models of rational individual choice. Instead, Tversky and Kahneman suggested that the differences could be explained in terms of mental or cognitive processes, specifically by assuming that "going to the theatre" is normally viewed as a transaction, in which the cost of the ticket is exchanged for the experience of seeing the play. Loss of the ticket would then mean debiting a "topical mental account" set up for the particular topic of play+going; whilst loss of the cash would not. According to this theory, the mental framing of the problem, or the structuring of these hypothetical mental accounts affects the purchasing decision. 
In the light of these and similar concepts, like framing and transactionutility, marketing scientists have been exploring ways of influencing the structure of customers' hypothetical mental accounts, for a given transaction, in order to influence behavior and increase the seller's profits (e.g., Puto, 1987; Urbany, 1988).

\section{Framing}

The particular concept of "Framing" also refers to the form of presentation of "risky" economic objects-of-choice, like gambles. In Kahneman and Tversky (1979), independent groups of subjects were offered the following two equivalent risky choices:

1. (Imagine that...) in addition to whatever you own you have been given $\$ 1000$. You are now asked to choose between: "A $50-50$ chance of $\$ 100$ or $\$ 500$ with certainty."

2. (Imagine that ....) in addition to whatever you own, you have been given $\$ 2000$. You are now asked to choose between: "A $50-50$ chance of a loss of $\$ 1000$ or a certain loss of $\$ 500$."

For the first question, a clear majority chose the certain $\$ 500$ alternative; but with the second question, a clear majority chose the risky gamble. This is a surprising result because the objects-of-choice in the two versions are identical in terms of the wealth-related outcomes and the stated probabilities. This finding, often replicated, confirms that preferences are very much influenced by the presentation of a "deal" involving risk, rather than its objective economic substance. These findings, and many similar ones, are all accommodated and explained by the detailed decision models proposed in Prospect Theory and Transaction Utility Theory. These new models are variants of the subjective expected utility (SEU) model used to explain risky choice in economic theory, but they also include representations of cognitive processes, like the psychological editing of information.

\section{Transaction Utility}

The basic SEU model of consumer choice simply involves assigning quantitative utilities to the possible outcomes of decision, then taking expectations, or probability-weighted averages, of these utilities. According to
this model, the alternative with the highest expected utility should be chosen. The basic model is viewed usually as a prescriptive model, yielding the rational choice alternative; but it may also be viewed as a descriptive model, capable of being falsified and modified through empirical testing. Subsequent modifications that improve the predictive power of the model then become useful as a base from which to develop practical marketing techniques.

Most variants and modifications of the basic SEU model are purely mathematical extensions, making no assumptions whatever about internal mental or cognitive processes (e.g., Schoemaker, 1982). However, Prospect Theory and Transaction Utility Theory are a radical departure from these black-box models and towards cognitive models involving hypothesized mental mechanisms. They may be said to "break the sacred boundary of the skin," in striving to accurately explain and predict consumer-choice. In 
the new models, cognitive or mental processes such as the detection and editing of information are represented. In addition, parameters of TUT include subjective mental constructs, such as a perceived reference-price, rather than objective prices (a distinction that has ethical implications to be explored later). Several specific empirical findings about behaviour may then be explained. For example, in addition to the robust results already described, the new models also accurately predict that:

- Most people, as consumers, would prefer "segregated gains" over combined gains of equivalent economic value (e.g., most people believe that a person would be "happier" to win $\$ 50$ plus $\$ 25$ in separate lotteries, rather than $\$ 75$ in one; Thaler, 1985, p. 203).

- If a given dollar payment can be framed in the mind of a buyer (customer) as a reduction in a large gain (rather than an absolute loss) then the "displeasure" or loss-of-value associated with that payment will be small. This is deduced from the shape of the value function in the theories (Figure 1).

Marketing scientists have been quick to recognize the practical implications of such findings. Three examples are given here: First, the perceived value of a product could be increased by separately identifying the desirable features or attributes (reflecting the first finding above). Next, Thaler (1985, p. 209) has suggested that sellers might use "tie-ins" to increase their total sales, because the extra payment made for the minor item would be framed as only a small value-loss, because of the concave shape of the value function in the model. Finally, Puto (1987) has proposed that customers could be lured to a retail outlet through (sold-out or apparent) bargain offers so that a decision to buy nothing would be framed as a "loss" (a topical mental account with a debit balance) and then, according to the new theories, risky purchases would become more attractive to the customer. 1

\section{Market-Clearing and Marketing Tactics}

Although the new models were deduced from micro-level behavioral data, they have also subsequently been used to predict or explain some aggregate level market phenomena (e.g., Thaler, 1985; Russell and Thaler,

FIGURE 1. A hypothetical value function. Source: Kahneman and Tversky (1979).

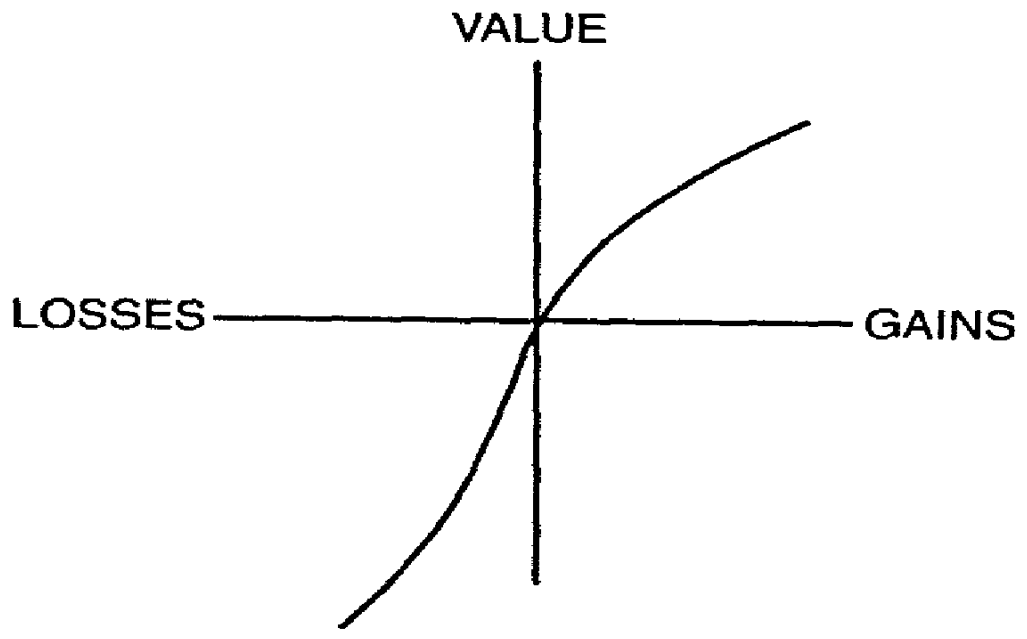


1985; Kahneman et al., 1986). The TUT model has enabled a specification of conditions under which consumer markets will fail to clear (i.e., where prices are such that supply and demand do not balance). Thaler (1985) explained the non-clearance of some markets, like the market for "superbowl" tickets in the U.S. (where demand is very high but official prices are only moderate) by pointing to the large negative transaction-utility associated with the very high price needed to clear the market. "Transaction utility" represents the idea that people often attach utility to a deal per se, that is independent of the economic value of the goods actually acquired. According to the theory, transaction utility is a function of the perceived reference price, which in turn depends on several factors, including the perceived fairness of a deal.

Therefore, according to TUT, marketing techniques aimed at manipulating the perceived reference price could facilitate the market-clearing process. That is, if the perceived reference price can somehow be raised, then people would be willing to pay the higher actual clearing price, without any loss of goodwill resulting from a "bad deal." Thaler (1985) offers the following examples of how, according to the theory, actual prices might be raised without reducing demand:

- raising the perceived reference price (for example, by discounting from an advertised retail price, a practice known as "double pricing," although there may be legal constraints),

- increasing the perceived costs incurred by the seller (as in the creation of an expensive image for the seller),

- obscuring the reference price (for example by changing the format of the product),

- using minimum-purchases or tie-ins (i.e., "integrate" the buyer's payments, to reduce the buyer's perceived value-loss from the total payment).

Thaler suggested that, for the purpose of applying the theory in this way, the metaphor of the consumer or buyer as a "pleasure-machine" is appropriate. Therefore the ethical case for or against the use of these and similar techniques rests partly on an acceptance of the pleasure-machine metaphor. The ethical issue surrounding the applications of these models are now explored, using three themes (i) utilitarian justification (ii) exploitation of cognitive habits, and (iii) scientific status.

\section{(i) Utilitarian Justification}

It seems reasonable to assume that facilitating the market clearing process by using these techniques would make a positive overall contribution to economic welfare. For example, balancing supply with demand through the price mechanism prevents the creation of "black markets," or other more arbitrary allocations of resources. So, there are at least some contexts where use of the model-based tactics might be ethically justified. However, these selling and marketing techniques can be applied also to a wide range of marketing situations, where the same justification is not available.

Thaler (1985) suggested the above tactics to facilitate market clearing. However, subsequent related research in consumer-behavior (e.g., Puto, 1987; Urbany et al., 1988) has not been restricted to the originally discussed 
case of non-clearing markets. In fact, the same techniques for raising prices or profits might be employed by marketers in many different contexts. This includes cases where markets fail to clear because prices are already too high (so that raising reference prices further would artificially restrict the goods to an even wealthier minority) or in cases where the seller has effective market power over the supply of a good, including even basic goods like water, electricity, telecommunications, etc.

Marketers who are motivated purely to increase sales or profit in the short term have no pragmatic reason, relating to the nature of the market or the goods, to resist using these tactics for raising prices. From a marketer's perspective, these techniques can be used to increase profits for almost any given product or service. In the case of electricity, for example, the technique of shifting the reference price has been widely used in practice (by shortening the billing cycle). However, the utilitarian ethical argument is far less plausible in cases like electricity supply, than in cases like superbowl tickets. For basic goods, it is the lack of actual (rather than perceived) ability of some consumer to pay for something they desperately need, that should be evaluated ethically (cf., Goldman, 1980). In essence, marketing tactics shaped around the new models may well induce a higher perceived reference price for, say, electricity, but this perception adds nothing to the less-wealthy customer's real ability to pay for the goods.

According to theories like TUT, the seller can increase the "value of buying a good" either by increasing the transaction-utility (by, for example, altering the reference price) or by increasing "acquisition utility," by reframing the objects of choice. As ethical justification, it could be argued that reframing a "deal," or encouraging the setting up of a particular system of mental accounts, can actually make the customer feel better, or create happiness. This argument, however, is seriously flawed. First, the psychological phenomenon that "we value events under the descriptions we put on them" (cf., Schick 1987) does not automatically grant others a moral license to describe events for us, in clever pursuit of their own self-interest and at our possible economic cost! (This practice could even be described as "Framing by framing.") Second, precisely the same argument could license the use of any device, including outright lies, that deceptively increases perceived "value" for the buyer at the time of purchase.

A final obstacle to any attempted utilitarian ethical justification for these tactics, concerns the interpretations of "value" and "utility" in the new models. The concept of "utility" in traditional SEU models arises from the need to satisfy particular abstract axioms, or postulates of "rationality" (such as transitivity of preferences). In contrast, the "Value-Function" of PT and the "Acquisition-Utility" of TUT, which operate after mental editing processes, can only be interpreted as measures of internal psychological states (i.e., using the pleasure-machine metaphor). Thus, when used in these new models, the meaning of "utility" has changed and now represents something like an internal-state parameter for the individual. This concept of utility in the "pleasure machine" metaphor contrasts markedly with the idea of measurable overall costs and benefit in ethical utilitarianism. Historically, ethical theory has considered these costs and benefits to be de- 
fined in terms of concepts like "happiness," "fulfiliment," "human-potential" and even "friendship." Therefore all of these conceptions of utility in ethics are very remote from the new behavioral models and the data that has driven them.

\section{(ii) Strategically Exploiting Cognitive Habits}

A second basic theme in the ethical appraisal concerns the more general idea of exploiting another person's reasoning and cognitive habits. In order to structure the discussion of this theme, the buyer or consumer is considered here as a cognitive system having beliefs, goals and a capability of making inferences. Accordingly, attempts at influence or deception could be directed at (i) the buyer's beliefs and perceptions, or (ii) the buyer's use of general rules and cognitive heuristics. The relevant ethical issues and arguments then apply a forteriori to the use of the pleasuremachine metaphor in the marketplace, since the new marketing tactics are a special case of manipulating others' perceptions and cognitive mechanisms.

\section{Buyer's Beliefs and Perceptions}

First, a seller can focus on the buyer's beliefs. For example, a product might be falsely advertised or labelled (e.g., "waterproof" watches). Such false claims are obviously unethical and normally illegal. Gardner (1975) described them as "unconscionable lies." Yet ethically there may be little difference between deceiving someone with natural-language statements and deceiving them by creating an expensive "image" for a cheap product, in order to increase the perceived reference price, as suggested by the TUT model.

A related marketing tactic is where the seller conceals those facts about the product that could adversely affect the purchase decision. Such "nondisclosure" tactics often concern a product's operating characteristics (such as the high power-consumption of some cheap appliances). In making a purchase decision, the customer might completely overlook the non-disclosed product attribute; or alternatively might make inappropriate inferences about those characteristics, from the information that is readily available. There are many reported examples of this form of deception: - Claiming (truthfully) that a brand of washing powder "contains blue crys-
tals," inviting the false inference that crystals improve cleaning power (Gardner, 1975).

- Pricing with a quantity surcharge, which exploits the (often appropriate) heuriscic "If the pack is larger then price-per-unit is lower" (e.g.. Nason and Della Bitta, 1983; Zotos, 1989).

- Marketing cheap brands of dishwashing liquids that are actually the most expensive in terms of price-per-dish-washed. "Some consumers confuse the mapping from price-per-bottle to price-perdish-washed" (Russell and Thaler. 1985).

- Using nutritional labels on food products, to create a (false) impression that the product can provide protection against diseases such as cancer. 
It is difficult to justify these particular non-disclosure tactics, ethically. They fail to meet conventional ethical criteria such as universalizability, fairness, etc. Moreover, even their legality has been debated in the U.S., with a view to making "affirmative disclosure" mandatory (cf., Buccholz, 1982). Yet these marketing tactics are also quite similar in spirit to those associated with the TUT model. Non-disclosure tactics, like some of the above tactics for raising prices, all involve "encouraging inappropriate inferences." For example, deliberately obscuring the reference price is basically similar in spirit to using a quantity surcharge. Thus the ethical objections apply with roughly similar force to both types of tactic.

\section{Buyer's Cognitive Heuristics}

There is a close parallel between deliberately encouraging a buyer or consumer to misuse common choice-heuristics and the new practice of targeting particular cognitive heuristics. Cognitive heuristics are hypothesized mental processes (procedures or mechanisms) that underlie quantitative judgments that in turn might affect buyer's preferences. Given the large and growing literature on behavioral decision theory and its applications, the absence of previous discussion of the ethical issues involved in exploiting cognitive heuristics seems particularly surprizing.

The Availability Heuristic (Tversky and Kahneman, 1973) provides a clear illustration of these issues. This heuristic links the judged probability of an event to the ease of imagining that event. Marketers can exploit this cognitive heuristic to increase sales. For example, sales of earthquake insurance may be increased by furnishing vivid images of earthquakes. These messages, known as "fear-appeals," arouse anxiety; but they also act psychologically to make the event seem more likely than it actually is. The technique is not always completely unethical, since it could be used in the real interests of the customers and society, such as promoting the use of safety belts. However, there are several reasons why the indiscriminate and systematic targeting of such cognitive heuristics may be unethical.

First, Hamlin (1986) has noted that heuristic-use by the individual might be viewed as a "cognitive precommitment"; that is, the decision-maker has bound himself, like legendary Ulysses to his ship's mast, in order to save cognitive resources in the future. This means that targeting heuristic-use can be likened to "mugging" someone whose hands are tied, as compared with someone who is free to fight back. Second, cognitive errors do not arise from heuristic use per se but from a failure to realize that their use might be inappropriate in a particular context. Deliberate targeting of the misapplication of useful heuristics exploits that precise point of buyers' vulnerability, in a way that could be considered as predatory.

Finally, buyers who realize that their cognitive and choice heuristics are being systematically manipulated, might feel some resentment. They would be in a very similar position to informed victims of subliminal advertising (e.g., Crisp 1987) whose perceptual processes have been systematically targeted by marketers. Indeed, many of the ethical objections that have been voiced in connection with the commercial use of subliminal messages (manipulative, denial of autonomy, etc.) could also be directed to the targeting of cognitive heuristics. Although subliminal advertising is no longer prac- 
ticed, it certainly provoked controversy and moral outrage when originally introduced on an experimental basis. It was widely condemned as being deceptive and unethical. It is also now illegal. Yet these ethical objections to targeting cognitive heuristics also apply to the targeting of the metaphorical "pleasure machine" with tactics like "obscuring the reference price". These marketing tactics deliberately target the buyers' frames (or percepts) and mental accounts (or heuristics).

\section{(iii) Scientific Status as a Justification}

The third and final overall theme in this ethical evaluation concerns the status of Prospect Theory and Transaction Utility Theory within a scientific psychology of the individual. These modified SEU models seem to have all the appearance of normative or prescriptive decision models; but at some point in their development, prescription has given way to prediction as the "sole purpose" (Thaler, 1985). If the latter interpretation is accepted, it is then necessary to consider the overall social consequences of these behavioral predictions being made and used as a basis for marketing techniques.

First, in strategic contexts, such as interactions between buyers and sellers, the assumptions made by each party about the other's capabilities and preferences tend, over time, to exert a mutual influence on the actual behavior of both parties. If buyers are manipulated, they are more likely to respond with manipulative behavior of their own. Moreover, there seems to be a widespread tendency to underestimate the strength of such interactive effects in strategic contexts (e.g., Axelrod, 1984). Therefore, when marketing practitioners treat customers as though they were merely confused and predictable automata, by using tie-ins, obscuring the reference price, or by manipulating perceptions of the seller's cost, they could be actively contributing to degradation of the overall market environment.

Secondly, if marketers are going to view these models simply as a basis for purely scientific prediction, then "Science" itself will once more have become a mere tool or instrument for exerting control over others. There is a sense in which this attitude towards scientific developments could be compared to the application of nuclear physics to deliberately gain mastery or dominance over others. With the new marketing techniques, science is once again in some danger of being subverted, in the name of commercialism or profit, into a tool for exercising control. At the very least, therefore, it would be wrong to seek to justify the use of these techniques by claiming that they are "scientific and hence value-free."

\section{Conclusions and Recommendations}

In accordance with this ethical evaluation and appraisal of marketing techniques based on cognitive models, it is now recommended that:

- Legislators in consumer-protection should consider extending the concept of "deceptive practice" to include tactics shaped around cognitive models and heuristics, like (a) targeting the availability heuristic to promote ovennsur- 
ance, (b) "obscuring the reference price" in markets where prices and profitability are already high, or (c) using unavailable loss-leaders to induce risky purchasing behavior in stores, etc.

- Teachers of marketing should emphasize the possible social consequences of indiscriminate application of the associated marketing techniques. They should not present the tactics as objectively scientific and value-free.

- Marketing experts could consider the possible benefits from consumer education programmes warning of these tactics [directly echoing Schwenk's (1986) suggestion that managers might defend themselves against manipulation].

- Researchers in consumer behavior could help to characterize those situations (if any) where the use of the above tactics can be broadly justified on social or economic grounds.

Finally, it is recommended that anyone who deliberately uses any device or technique that exploits the systematic but fauly cognitions of others, for their own advantage, should also consider the various distinctive ethical issues that have been outlined in this article.

\section{Note}

1. This argument invokes the PT value-function, noting the hypothesized risk-seeking tendency in the domain of perceived losses, indicated by the shape of the function (Figure 1). Similar arguments are found in Whyte, 1986.

\section{References}

Axelrod, R.: 1985, The Evolution of Co-operation (Basic Books, New York).

Buccholz, R. A.: 1982, Business Environment and Public Policy (Prentice Hall: Englewood Cliffs, N.J.).

Crisp, R.: 1987, 'Persuasive Advertising, Autonomy and the Creation of Desire,' Journal of Business Ethics 6, 413-18.

Gardner, D. M.: 1975, 'Deception in Advertising: A Conceptual Approach,' Journal of Marketing 39, 40-6.

Goldman, A. H.: 1980, 'Business Ethics: Profits, Utilities and Moral Rights,' Philosophy and Public Affairs, 260-85.

Hamlin, A. P.: 1986, Ethics, Economics and the State (Wheatsheaf: Brighton).

Kahneman, D., Knetch, J., and Thaler, R.: 1986, 'Faimess as a Constraint on ProfitSeeking: Entitlements in the Market', American Economic Review 76, 728-41.

Kahneman, D. and Tversky, A.: 1979, 'Prospect Theory: An Analysis of Decision under Risk', Econometrica 47 (2), 263-91.

Kahneman, D. and Tversky, A.: 1984, 'Choice, Values and Frames', American Psychologist 39, 341-50.

Nason, R. W., and Della Bitta, A. I.: 1983, "The Incidence and Consumer Perceptions of Quantity Surcharges', Joumal of Retailing 59(2), 40-54.

Neale, M. A. and Bazerman, M. H.: 1985, 'Perspectives for Understanding Negotiation', Joumal of Conflict Resolution $29(1), 33-55$.

Puto, C. P.: 1987, "The Framing of Buying Decisions', Joumal of Consumer Research 14, 301-15.

Russell, T. and Thaler R: 1985. "The Relevance of Quasi-Rationality in Competitive Markets', American Economic Review 75(5), 1071-82. 
Schick, F: 1987, 'Rationality, a Third Dimension', Economics and Philosophy 3, 49-66. Schoemaker, P. J. H.: 1982, 'The Expected Utility Model: Its Variants, Purposes, Evidence and Limitations*, Joumal of Economic Literature 30 (June), 529-63.

Schwenk, C. R.: 1986, 'Information Cognitive Biases, and Commitment to a Course of Action', Academy of Management Review 11, 293-310.

Sheffrin, H, M., and Statman, M.: 1984, 'Explaining Investor Preferences for Cash Dividends', Joumal of Financial Economics 13, 253-82.

Singer A. E., Singer, M. S. and Ritchie G.: 1986, 'The Role of Transactions in Mental Accounting', Psychological Reports 59, 835-8.

Thaler R.: 1985, 'Mental Accounting and Consumer Choice', Marketing Science 4, $199-214$.

Trersky, A. and Kahneman D.: 1981, 'The Framing of Decisions and the Psychology of Choice', Science 211, 453-58.

Tversky, A., and Kahneman D.: 1973, 'Availability: A Heuristic for Judging Frequency and Probability', Cognitive Psychology 5(2), 207-32.

Urbany, J. E., Bearded, W. O. and Weilbaker, D. C.: 1988, 'The Effect of Plausible and Exaggerated Reference Prices on Consumer Perception and Price Search', Joumal of Consumer Research 15 (June), 95-110.

Whyte, G.: 1986, 'Escalating Commitment to a Course of Action: A Reinterpretation', Academy of Management Review 11 (2), 311-21.

Zotos, Y: 1989, 'The Incidence and Consumer Perceptions of Quantity Surcharge in Greece', Working Paper, University of Canterbury. 